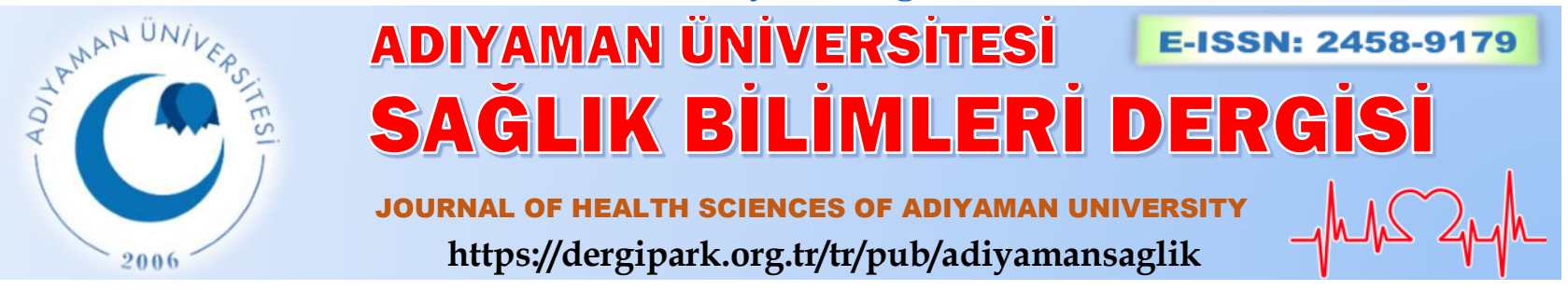

\author{
Özgün Araştırma/Research Article
}

\title{
Hemşirelerin meme kanseri endişe düzeyi ile erken tanı uygulama davranışları arasındaki iliş ki
}

\section{Relationship between nurses' breast cancer concern level and early diagnosis application behaviors}

\author{
Nazife BAKIR 1 @(D), Cuma DEMIR ${ }^{1}(\mathrm{i})$ \\ ${ }^{1}$ Burdur Mehmet Akif Ersoy Üniversitesi, Bucak Sağl1k Yüksekokulu, 15300, Burdur-Türkiye
}

\begin{abstract}
Atıf gösterme/Cite this article as: Bakır N, Demir C. Hemşirelerin meme kanseri endişe düzeyi ile erken tanı uygulama davranışları arasındaki ilişki. ADYÜ Sağllk Bilimleri Derg. 2020;6(2):216-222. doi:10.30569.adiyamansaglik. 731912
\end{abstract}

Öz

Amaç: Bu araştırma hemşirelerin meme kanseri endişe düzeyi ile erken tanı uygulama davranışları arasındaki ilişkinin belirlenmesi amacıyla yapılmıştır.

Gereç ve Yöntem: Nicel-tanımlayıcı tipteki bu çalışma Ocak 2020-Şubat 2020 tarihleri arasında yapılmış olup, araştırmanın örneklemini Akdeniz Bölgesindeki bir Devlet Hastanesinde çalışan 162 kadın hemşire oluşturmaktadır. Veri toplama formu olarak; tanımlayıcı özellikler formu ve Meme Kanseri Endişe Ölçeği kullanılmıştır.

Bulgular: Hemşirelerin \%69,1'inin kendi kendine meme muayenesi yaptığı, \%53,7'sinin klinik meme muayenesi yaptırdığ 1 ve \%8,6'sının ise mamografi yaptırdığ 1 belirlenmiştir. Hemşirelerin \%64,8'inin meme kanseri endişe düzeyinin yüksek olduğu ve Meme Kanseri Endişe Ölçeği puan ortalamasının $12,60 \pm 3,94$ olduğu saptanmıştır. Lojistik regresyon analizinde kendi kendine meme muayenesi yapanların yüksek düzeyde meme kanseri endişesinin olduğu görülmüştür.

Sonuç: Çalışmamızda hemşirelerin yarıdan fazlasının yüksek düzeyde meme kanseri endişesi yaşadığ1 belirlenmiştir.

Anahtar Kelimeler: Hemşire; Meme; Kanser; Endişe.

\begin{abstract}
Aim: This research was conducted to determine the relationship between nurses' breast cancer anxiety level and early diagnosis application behavior.

Materials and Methods: This quantitative and descriptive study was conducted between January 2020 and February 2020, and the sample of the study was 162 female nurses working in a State Hospital in the Mediterranean Region. As data collection form; descriptive features form and Breast Cancer Anxiety Scale were used.

Results: It was determined that $69.1 \%$ of the nurses performed breast self-examination, $53.7 \%$ had clinical breast examination and $8.6 \%$ had mammography. In logistic regression analysis, it was observed that nurses who performed breast self examinations had a high level of breast cancer concern.

Conclusion: In our study, it was determined that more than half of the nurses experienced a high level of breast cancer concern.
\end{abstract}

Keywords: Nurse; Breast; Cancer; Anxiety.

Yazışma Adresi/Address for Correspondence: Nazife BAKIR, Burdur Mehmet Akif Ersoy Üniversitesi Bucak Sağllk Yüksekokulu, 15300, Burdur-Türkiye, E-mail: nazbakir@ hotmail.com

Geliş Tarihi/Received:04.05.2020 Kabul Tarihi/Accepted:09.06.2020

Yayım Tarihi/Published online:30.08.2020

Bu eser, Creative Commons Atıf-GayriTicari 4.0 Uluslararası Lisansı ile lisanslanmıştır. Telif Hakkı @ 2020 Adıyaman Üniversitesi Rektörlügü 


\section{Giriş}

Kanser, global olarak önemli bir morbidite ve mortalite kaynağı olarak tanımlanmaktadır. Sağlıksız diyetler, sedanter yaşam tarzı, sigara ve alkol içmek gibi davranışsal yaşam tarzının benimsenmesi nedeniyle kanser yükü daha da artma potansiyeline sahiptir. ${ }^{1}$ Türkiye'de 2015 y1lında kanser insidans1 100.000'de 212,6'dır. Bu oran erkeklerde 100.000'de 247,6 iken kadınlarda 100.000'de 177,5'tir. Yeni kanser vakası olan kişi sayısı ise 167.463 'tür. 2030 yılında yeni kanser vaka sayısının 22 milyon olmasi tahmin edilmektedir. Dünyada meme, kolorektal ve serviks kanserleri kadınlarda ilk üç kanser türünü oluştururken;bu sıralama Türkiye'de meme, tiroit ve kolorektal kanser olarak görülmektedir. ${ }^{2}$

Meme kanseri kadınlar arasında dünyadaki en yaygın kanserlerden biridir. $^{3}$ Gelişmiş ülkelerdeki kadınlarda daha yüksek oranlarda meme kanseri görülmekle birlikte global olarak tüm bölgelerde insidansı artmaktadır. ${ }^{4}$ GLOBOCAN verilerine göre, tüm yeni kanser vakalarının \%25'ni meme kanserleri oluşturmaktadır içermektedir. ${ }^{3}$ 2018'de tüm dünyada 2,1 milyon kadın meme kanserine yakalanmıştır. Bunların 630.000'ni geç tanı ve tedaviye ulaşamama sebebiyle hayatını kaybetmiştir. ${ }^{4}$ Meme kanseri taraması, meme kanseri ölümlerini azaltmada etkili bir araç olduğu literatür tarafından teyit edilmektedir. ${ }^{5}$ Meme kanserinde erken tanı konulması, hayatta kalma oranını ve tedavi başarısını önemli ölçüde etkilemektedir. Kesin koruyucu bir yöntemi bulunmayan meme kanserine karş1 erken dönemde tanı konulması önemlidir. Meme kanseri için erken tanı yöntemleri: Mamografi, klinik meme muayenesi (KMM), kendi kendine meme muayenesidir (KKMM). ${ }^{6}$

Meme kanserine yakalanma konusunda birçok kadının endişe yaşadığı bilinmektedir. ${ }^{7}$ Literatürde kanser endişesi, kanser tehdidine karş1 duygusal bir tepki olarak tanımlanmaktadır. ${ }^{3}$ Kansere yakalanmaya yönelik endişe, kişiyi erken tanı ve tedaviye sevk edecek sağlıklı yaşam biçimi davranışları kazandırmak önemli bir etkendir. ${ }^{8}$ Yüksek oranlarda meme kanserinin görülmesi, meme kanseri riski endişesinin ve farkındalığının artmasına sebep olmaktadır. Kadınların meme kanserine yakalanma endişesi, meme kanserine karşı sağlı̆̆ koruyucu davranışlar sergilemesinde etkilidir. Örneğin aile öyküsünde meme kanseri tanısının olması, kadının meme kanserine olan algısını ve endişe düzeyini yükseltmekle birlikte koruyucu sağlık davranışları kazanmasını da sağlayabilmektedir. ${ }^{9}$

Ülkemizde sağlık çalışanlarının meme kanseri bilgi düzeyleri hakkında çalışmalara rastlanmakla birlikte, ${ }^{10,11}$ topluma göre daha fazla meme kanseri vakalarıyla karşılaşan sağlık çalışanlarının meme kanseri endişe düzeyleri hakkında herhangi bir çalışmayla karşılaşılmamıştır. $\mathrm{Bu}$ çalışmanın amacı hemşirelerin meme kanseri endişe düzeyi ile erken tanı uygulama davranışları arasındaki ilişkinin belirlenmesi amaçlanmıştır.

\section{Gereç ve Yöntem}

\section{Araştırmanın tipi}

Nicel-tanımlayıcı tipteki bu çalışma Ocak 2020- Şubat 2020 tarihleri arasında Akdeniz Bölgesindeki bir Devlet Hastanesinde görev yapan hemşirelerle yürütülmüştür.

\section{Araştırmanın evreni ve örneklemi}

Araştırmanın evreni Akdeniz Bölgesindeki bir Devlet Hastanesinde görev yapan 200 kadın hemşire oluşturmaktadır. Araştırmada evrenin tamamına ulaşılması hedeflenmiş olup araştırmanın yapıldı ğ 1 tarihlerde araştırmaya katılmayı kabul eden ve izinli olmayan 162 hemşire (evrenin \%81'i) örneklemi oluşturmuştur.

\section{Veri toplama araçları}

Hemşirelere "tanımlayıcı özellikler formu" ve "meme kanseri endişe ölçeği" uygulanmıştır.

\section{Tanımlayıcı özellikler formu}

Hemşirelerin sosyo-demografik özelliklerini incelemeyi sağlayan; yaş, eğitim düzeyi, medeni durum, çocuk sayısı, aile gelir durumu, hangi klinikte çalıştığı, kaç yıl çalıştığı ve sigara kullanma durumunu ile erken tanı davranışlarını sorgulayan KKMM yapma durumu, KMM yaptırma durumu, mamografi çektirme durumunu sorgulayan 11 sorudan oluşmaktadır. 


\section{Meme kanseri endişe ölçeği}

Lerman ve arkadaşları 1991 yılında Meme Kanseri Endişe Skalası (MKES) üç maddelik ilk halini geliştirmişlerdir. Geliştirilen MKES'nın ilk hali meme kanseri endişesinin günlük aktivitelere ve ruh haline etkisini ölçmektedir. Günümüzde Lerman, MKES'i genel kansere uyarlamış ve soru sayısını altıya çıkartmıştır. ${ }^{12}$ Lerman'ın bu 6 maddelik genel kansere uyarlamış skalası TimurTaşhan ve arkadaşları tarafından 2018 yılında meme kanserine uyarlanarak MKES'in Türkçe geçerlik ve güvenirliliği yapılmıştır. MKES 5'li likert tipindedir ve seçenekler 0 ile 4 puan arası puanlanmaktadır. MKES'den en düşük 0 en yüksek 24 puan alınabilmektedir. MKES toplam puanı $<12$ ise kanser endişesinin düşük düzeyde, MKES toplam puanı $\geq 12$ ise kanser endişesi yüksek düzeyde olduğunu göstermektedir. Türkçe'ye uyarlanmış MKES'in Cronbach $\alpha$ değeri 0,78' dir. ${ }^{13}$ Araştırmamızda Cronbach $\alpha$ değeri 0,81 'dir.

\section{Verilerin toplanması}

Veriler araştırmacılar tarafindan araştırmanın yapıldı ğı Devlet Hastanesinde çalışan hemşirelere normal tedavi ve bakım işleyişini bozmadan uygun vakitlerde araştırmacılar tarafından yüz yüze görüşme yöntemi ile toplanmıştır.

\section{Verilerin analizi}

Araştırmada sağlanan verilerin değerlendirilmesinde SPSS 20.0 paket programı kullanılmıştır. Veri dağılımının normalliğini değerlendirmek için ShapiroWilk testi kullanılmıştır. Değerlendirmede yüzde, frekans, One-Way ANOVA, Indenpendent Samples t-test ve lojistik regresyon analizi kullanılmıştır. Anlamlılık düzeyi $p<0,05$ olarak kabul edilmiştir.

\section{Bulgular}

Araştırmaya katılan kadın hemşirelerin $\% 56,2$ 'sinin 35 yaş ve altında olduğu, $\% 48,1$ 'inin önlisans mezunu olduğu, $\% 84,8$ 'inin evli olduğu ve \%56,2'sinin 1-2 çocuğu olduğu saptanmıştır. \%50,6'sinin 10 y1l üzerinde çalıştı̆̆ $1, \% 51,2$ 'sinin dahiliye kliniklerinde çalıştığ \%69,1'inin KKMM yaptığ1, \%53,7'sinin
KMM yaptırdığg ve \%91,4'ünün ise mamografi yaptırmadığı saptanmıştır. \%64,8'inin MKE düzeyinin yüksek olduğu ve tüm hemşirelerin MKES ortalamasının

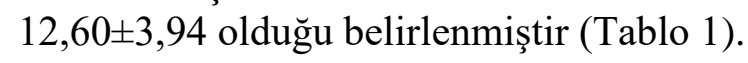

Araştırmada hemşirelerin MKE düzeyleri ile tanıtıcı faktörlerinin karşılaştırılması Tablo 2'de verilmiştir. Araştırmada çalışma y1lı 10 yıl ve altı olanların ve KKMM yapanların yüksek düzeyde meme kanseri endişesinin olduğu görülmüştür $(p<0,05)$.

Tablo 3'te meme kanseri endişesini etkileyen faktörlerin lojistik regresyon analizinde, KKMM yapanların Meme Kanseri Endişesi düzeyinin, KKMM yapmayanlara göre 3,025 kat daha fazla olduğu saptanmıştır.

\section{Tartışma}

Çalışmamızda hemşirelerin \%69,1'inin KKMM yaptığı, \%53,7'sinin KMM yaptırdığ 1 ve $\% 8,6$ 'sının ise mamografi yaptırdığ saptanmıştır. Nacar'ın Aile Sağlığ Merkezi'ne başvuran 18 yaş ve üzeri, meme kanseri tanısı almamış kadınlarla yaptığı çalışmasında katılımcıların \%18,3'ünün KMM, \%39,7'sinin KKMM yaptığı ve $\% 15,8$ 'inin ise mamografi çektirdiği belirlenmiştir. ${ }^{8}$ Gözüyeşil ve arkadaşlarının Aile Sağlığı Merkezi'ne başvuran 15-49 yaş arası kadınlarla yaptığ 1 araştırmasında ise KKMM yapma durumu \%7,1, KMM yaptırma durumu $\% 21,9$ ve mamografi çektirme durumu \%14,1 olarak saptanmıştır. ${ }^{9}$ Özoğul ve Sucu Dağ'ın Üniversitede çalışan kadınlarla yaptığı çalışmasında kadınların \%74,0'ünün KKMM yaptığ1, \%63,8'nin bir uzmana KMM yaptırdığı, \%57,9'nun mamografi çektirdiği saptanmıştır. ${ }^{14}$ Sağlık çalışanlarının meme kanseri KKMM ve mamografiye ilişkin inançlarının incelendiği bir çalışmada ise sağlık çalışanların KKMM yapanların oranı $\% 81,3$ her ay düzenli bu uygulamayı yapanların oranı \%21,9 olduğu saptanmıştır. KKMM uygulamasını yalnızca $\% 25$ 'i çok iyi bildiklerini, \%2,6's1 ise bu uygulamayı hiç bilmediklerini belirtmişlerdir. Sağlık çalışanlarının büyük bir kısmı $(\% 87,5)$ hiç mamografi çektirmediği ve düzenli olarak meme muayenesi için hekime gitmediği (\%85) belirlenmiştir. ${ }^{15}$ Araştırmamızda hemşirelerin mamografi yaptırma 
düzeylerinin düşük olmasının KKMM ve KMM'de riskli bir durumla karşılaşmamış olmamaları ve katılımcıların yarıdan

Tablo 1. Hemşirelerin tanıtıcı özelliklere göre dağılımı

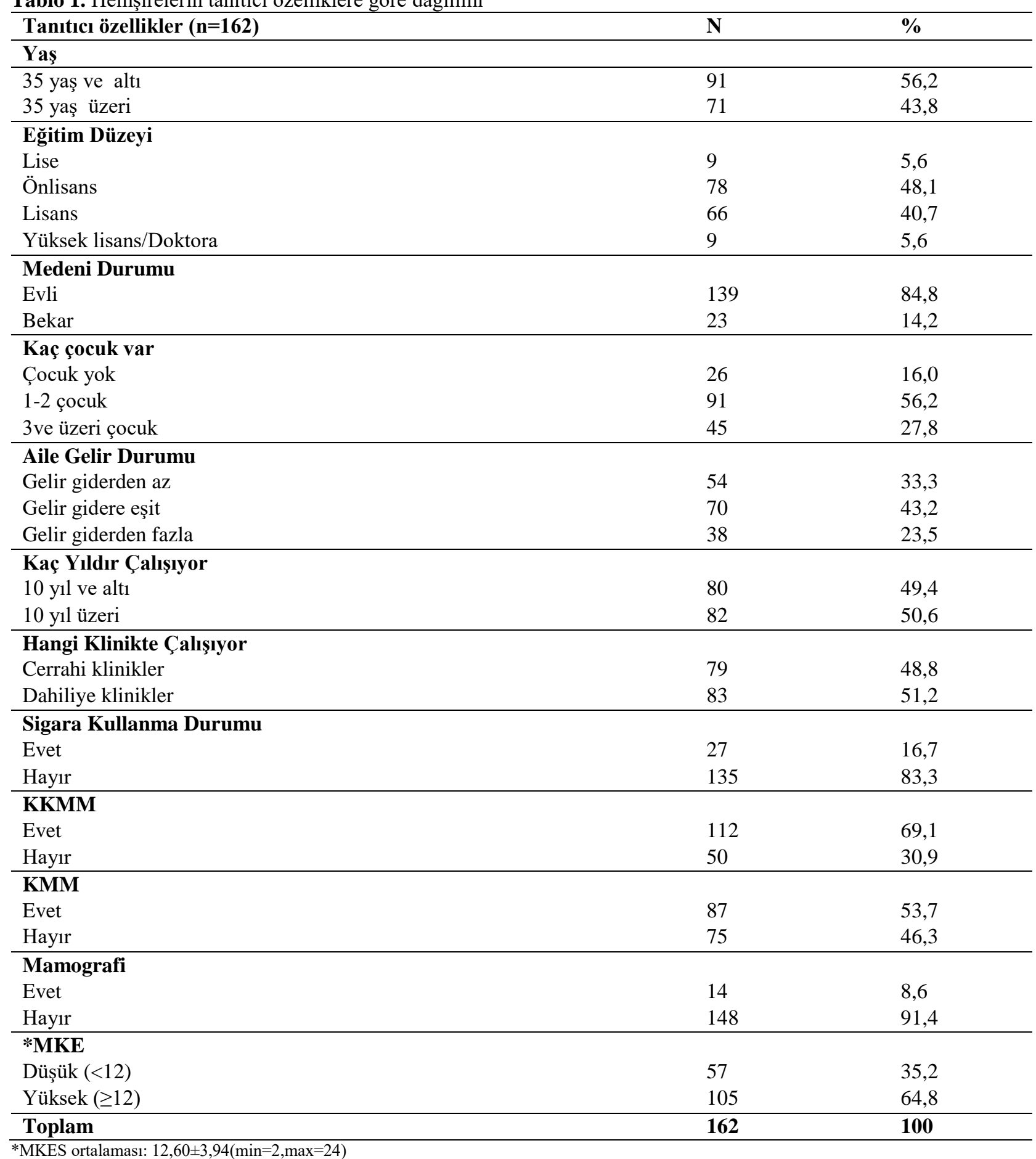

Așırı kanser endișesi olan hastaları tanımaları ve uygun koruyucu sağlık hizmetleri hakkında bilgi vererek bu endişeyi azaltmalarına yardımcı olmaları beklenen kadın hemşirelerin, bu çalışmada MKES puan ortalamasının $12,60 \pm 3,94$ olduğu ve hemşirelerin \%64,8'inin meme kanseri endişe düzeyinin yüksek olduğu saptanmıştır. fazlasının 35 yaş ve altında olmasından kaynaklı olabileceği düşünülmüştür. 
arkadaşlarının çalışmasında orta ve düşük düzeyde meme kanserine yakalanma endişesinin katılımcıların \%57'sinde var olduğu saptanmıştır. ${ }^{16}$ Literatüre ters yönde bulduğumuz hemşirelerin yarıdan fazlasının yüksek düzeyde meme kanseri endişesi taşımasının, onların sağlık konusunda bilgi düzeyinin bu endişeyi veya farkındalığı arttırdığı düşünülmüştür.

Tablo 2. Hemşirelerin meme kanseri endişe düzeyleri ile tanıtıcı faktörlerinin karşılaştırılması

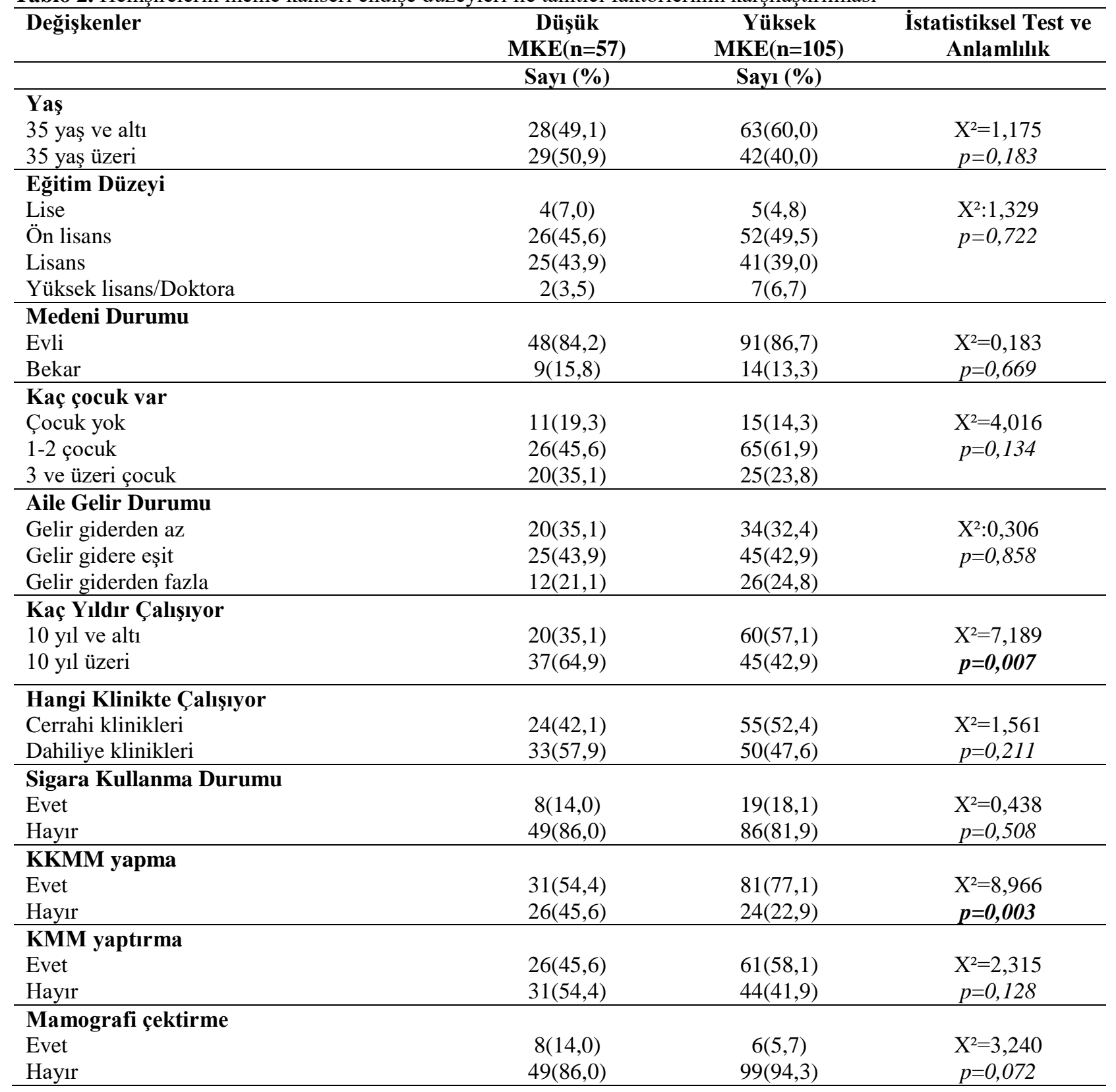

Tablo 3. Meme kanseri endişesini etkileyen faktörlerin lojistik regresyon analizi.

\begin{tabular}{lccccc}
\hline Değiş̧kenler & B & Wald & $\boldsymbol{p}$ & OR & \%95 Güven Aralı̆̆ \\
\hline Çalışma yılı & & & & & \\
10 yıl ve altı & $-0,570$ & 2,769 & 0,096 & 0,565 & $1,320-5,280$ \\
10 yıl üzeri & -- & -- & -- & -- & -- \\
\hline KKMM yapma & & & & & $1,478-6,195$ \\
Evet & 1,107 & 9,168 & $\mathbf{0 , 0 0 2}$ & 3,025 & -- \\
Hayır & -- & -- & -- & -- & \\
\hline
\end{tabular}

Çalışmamıza benzer şekilde meme kanseri vakaları ile karşılaşan kentsel mamografi merkezinde çalışan 250 kadınla yapılan bir çalışmada da kadınların \%63'ünde orta- yüksek düzeyde meme kanseri endişesinin var olduğu saptanmıştır. ${ }^{17}$ 
Kayg1, korku ve endişe meme kanseri taramasının çeşitli düzeylerde engelleri ve kolaylaştırıcıları olarak tanımlanmaktadır. ${ }^{5}$ Çalışmamızda KKMM yapan hemşirelerin meme kanseri endişesi düzeyinin, KKMM yapmayanlara göre 3,025 kat daha fazla olduğu saptanmıştır. Gözüyeşil ve arkadaşlarının çalışmasında da düzenli KKMM yapan kadınların meme kanseri endişelerinin daha fazla olduğu saptanmıştır. ${ }^{9}$ Nacar'ın çalışmasında ise klinik meme muayenesi yaptıranların, klinik meme muayenesi yaptırmayanlara göre 0,4 kat daha fazla meme kanseri endişesi taşıdığ saptanmıştır. ${ }^{8}$ Meme kanserine yakalanma konusunda belirli düzeyde endişe yaşamanın koruyucu davranışları uygulamaya yönelik teşvik edici olabileceği ancak endişe düzeyinin aşırı yükselmesinin ise kadınlar için danışmanlığı gerektireceği düşünülmüştür.

\section{Araştırmanın sınırlılıkları}

Çalışmanın bir merkezde yapılması ve katılımcıların meme kanseri hastalık öyküsü ve ailede hastalık öyküsü değerlendirilmemiş olması araştırmanın sinırlılığını oluşturmaktadır.

\section{Sonuç}

Çalışmamızda MKES ölçeği puan durumuna göre hemşirelerin yarıdan fazlasının yüksek düzeyde meme kanseri endişesi yaşadığı belirlenmiştir. $\mathrm{Bu}$ doğrultuda sağlık çalışanlarının meme kanseri endişe düzeylerinin belirlenmesine yönelik daha fazla çalışmanın yapılması, ancak çalışmaların sonucunda asıl değerlendirmenin psikiyatri bağlamında yapılması gerektiği ve gerçekten bir sorun saptanırsa danışmanlık alınması önerilir.

\section{Araştırmanın Etik Boyutu}

Araştırmaya başlamadan önce ilgili üniversitenin Girişimsel Olmayan Klinik Araştırmalar Etik Kurulu onayı (Tarih: 08.01.2020 Karar No: GO 2020/6) alınmıştır. Çalışma, Helsinki Bildirgesi ilkelerine bağlı kalarak yürütülmüştür.

\section{Bilgilendirilmiş Onam}

Araştırmaya katılan hemşirelere araştırmanın amacı ile ilgili bilgi verilip elde edilen bilgilerin sadece bu araştırma için kullanılacağı açıklandıktan sonra, sözlü ve yazılı onamları da alınmıştır.

\section{Yazar Katkıları}

Konsept: N.B., C.D., Dizayn: N.B., C.D., Veri Toplama veya İşleme: C.D., Analiz veya Yorumlama: N.B., Literatür Arama: N.B., C.D., Yazan: N.B., C.D.

\section{Teșekkürler}

Çalışmaya katılan tüm hemşirelere teşekkür ederiz.

\section{Çıkar Çatışması Beyanı}

Yazarların herhangi bir çıkara dayalı ilişkisi yoktur.

\section{Araştırma Desteği}

Çalışmayı maddi olarak destekleyen kişi/kuruluş yoktur.

\section{Beyanlar}

Çalışma daha önce herhangi bir yerde sunulmamıştır.

\section{Kaynaklar}

1. Nwozichi CU, Ojewole F, Oluwatosin AO. Understanding the challenges of providing holistic oncology nursing care in nigeria. Asia Pac J Oncol Nurs. 2017;4:18-22.

2. Türkiye Halk Sağlığı Kurumu 2015 Kanser istatistikleri, [Internet]. https://hsgm.saglik.gov.tr/tr/kanser-istatistikleri 20.02.2020 tarihinde erişilmiştir.

3. Choi E, Lee YY, Yoon HJ, Lee S, Suh M, Park B, et al Relationship between cancer worry and stages of adoption for breast cancer screening among korean women. Plos One. 2015;10(7):e0132351.

https://doi.org/10.1371/journal.pone.0132351

4. World Health Organization [Internet]. https://www.who.int/news-room/detail/18-12-2019-whoprequalifies-first-biosimilar-medicine-to-increase-worldwideaccess-to-life-saving-breast-cancer-treatment $\quad 20.02 .2020$ tarihinde erişilmiştir.

5. Consedine SN, Magai C, Krivoshekova SY, Ryzewicz L, Neugu IA. Fear, anxiety, worry, and breast cancer screening behavior: a critical review. cancer epidemiology. Biomarkers\&Prevention. 2004; 13(4):501-510.

6. Güzel N, Bayraktar N. Kadınların meme kanserinin erken tanısına yönelik farkındalıklarının ve uygulamalarının belirlenmesi. Hacettepe Üniversitesi Hemşirelik Fakültesi Dergisi. 2019;6(2):101-10 .

7. Hay JL, McCaul KD, Magnan RE. Does worry about breast cancer predict screening behaviors? a metaanalysis of the prospective evidence. Preventine Medicine. 2006;42(6):401408.

8. Nacar G. Kadınlarda meme kanseri endișe düzeyi ile erken tan uygulama davranışları arasındaki ilişki. İnönü Üniversitesi Sağlık Hizmetleri Meslek Yüksek Okulu Dergisi. 2018;6(2):4453.

9. Gözüyeşil E, Taş F, Düzgün AA. Factors affecting breast cancer worry and healthy lifestyle behaviors in women aged 15-49 years. Cukurova Medical Journal. 2019;44(4):1215-25. doi: $10.17826 /$ cumj. 493360

10. Soyak R. Hemşirelerin meme kanseri, meme kanseri risk faktörleri, belirtileri ve tarama yöntemlerine ilişkin bilgi 
düzeyinin belirlenmesi. [Yüksek Lisans Tezi] Sivas, Cumhuriyet Üniversitesi, Sağlık Bilimleri Enstitüsü; 2019.

11. Şeker N, Köksal YY, Özaydın E, Çapacı B, Okyay P. Üçüncü basamak sağlık kuruluşundaki hemşirelerin kanser tarama programları bilgileri ile tarama testlerini yaptırma durumları. Düzce Medical Journal. 2018;19(1):14-8.

12. Lerman C, Trock B, Rimer BK, Jepson C, Brody D, Boyce A. Psychological side effects of breast cancer screening. Health Psychol. 1991; 10(4):259-67.

13. Timur Taşhan S, Uçar T, Aksoy Derya Y, Nacar G, Erci B. Validity and reliability of the turkish version of the modified breast cancer worry scale. Iran $J$ Public Health. 2018;47(11):1681-87.

14. Özoğul E, Dağ SG. Üniversitede çalışan kadınların meme kanserinde erken tanıya yönelik sağlık inançları ve sağlık inançlarını etkileyen faktörler. DEUHFED. 2019;12(4):264-73.

15. Canbulat N. Sağlık çalışanlarının meme kanseri, kendi kendine meme muayenesi ve mamografiye ilişkin sağlık inançlarının incelenmesi.[Yüksek Lisans Tezi]. Erzurum, Atatürk Üniversitesi, Sağlık Bilimleri Enstitüsü; 2006.

16. Murphy PJ, Marlow LA, Waller J, Vrinten C. What is it about a cancer diagnosis that would worry people? A population-based survey of adults in England. BMC Cancer. 2018;8(1):86-6.

17. April-Sanders A, Oskar S, Rachel C. Shelton RC, et al. Predictors of breast cancer worry in a hispanic and predominantly immigrant mammography screening population. Women's Health Issues. 2018;27(2):237-44. 